\title{
FAKTOR YANG MEMPENGARUI KEBERHASILAN PESERTA DIDIK DALAM PEMBELAJARAN BAHASA INGGRIS

\author{
(Teori Linguistik dan Al-Qur'an)
}

\author{
Andi Muhammad Dakhalan \\ Institut Agama Islam Negeri(IAIN) Palu
}

\begin{abstract}
The emergence of today's role of English as an international language (EIL) and as a global lingua franca (ELF) makes English language education important in many countries. In Indonesia, for example, it has been growing a number of schools ranging from kindergarten to university level which use English as the medium of instructions.Every subject in school curriculum has different objectives including English subject. But some students donot realize that, learning English is really important in their life. It makes them unmotivated in learning English. Lack of learners' motivation is believed as one of the primary problems of English language teaching, many of them take it as a difficult lesson to learn. As a result, they skip class, and when they attend the class, it is not because they want to learn English but likely because they fear of failure. Moreover, lots of them may lack of attention during class, chatting with classmates, doodling in their note books or gasp in their textbooks. This present study aims at discovering the factors that influence the students' achievement in English language learning by using linguistic and Al-Qur'an theory. The conclusion of the study is the factors that influence the students' achievement in English
\end{abstract}


language learning are the students' intelligence, motivation, school facilities, policies of government and the principal, family, and environment.

Keywords: Factors, Achievement, and English Language Learning

\section{PENDAHULUAN}

Pembelajaran bahasa asing khususnya bahasa Inggris di bangku sekolah maupun di lingkungan perguruan tinggi selalu menjadi fokus perhatian, bahkan saat ini telah menjadi indikator penting dalam mengukur kadar keelitan sebuah lembaga pendidikan. Hal tersebut disebabkan karena bahasa Inggris merupakan salah satu bahasa internasional dan sebagai salah satu lingua franca yangmenjadikan bahasa Inggris dianggap penting di berbagai negara termasuk di Indonesia. Hal tersebut tercermin pada menjamurnya lembaga kursus bahasa Inggris yang merupakan efek dari peningkatan minat masyarakat dalam mempelajari bahasa Inggris. ${ }^{1}$

Pembelajaran bahasa sangat berbeda dengan pembelajaran subjek lainnya, idealnya pembelajaran bahasa Inggris itu lebih tepat jika menggunakan kata learn dibandingkan study hal ini sama dengan perbedaan pendekatan yang tepat pada penguasaan materi matematika dan berenang. Hal tersebut senada dengan pendapat McKay, "teaching of English as an International language (EIL) should be based on an entirely different set of assumptions that have typically informed English Language Teaching (ELT) pedagogy". ${ }^{2}$

Namun seiring dengan peningkatan minat masyarakat dalam mempelajari bahasa Inggris semakin banyak juga kendala yang muncul, jika tidak ditangani dengan cepat dan dengan solusi yang

${ }^{1}$ Yuwono, G. 2005. English Language Teaching in Decentralised Indonesia: Voices from The Less Priviledged Schools. Paper presented at the AARE 2005 International Education Research Conference.

${ }^{2}$ McKay, S. L. 2003. Toward An Appropriate EIL Pedagogy: Reexamining Common ELT Assumption. International Journal of Applied Linguistics, 13(1), pp. 1-22. 
tepat akan menjadi sebuah titik balik dimana bahasa Inggris itu menjadi sebuah subjek yang membosankan bahkan menakutkan bagi peserta didik.

Setiap subjek di sekolah atau kampus memiliki tujuan tertentu, akan tetapi beberapa peserta didik tidak menyadari hal tersebut. Khususnya bahasa Inggris, mereka belum menyadari betapa pentingnya menguasai bahasa Inggris bagi kehidupan mereka, padahal menguasai bahasa Inggris aktif meningkatkan daya saing mereka dalam menyambut MEA.

Selain berasal dari dalam diri peserta didik sendiri, adapula faktor penyebab external yang dapat mempengaruhi proses keberhasilan pembelajaran bahasa Inggris. Oleh karena isu tersebut penulis tertarik untuk menggambarkan faktor-faktor yang dapat mempengaruhi keberhasilan peserta didik dalam keberhasilan pembelajaran bahasa Inggris menurut para ahli linguistik dan menurut Al Qur'an pada tulisan ini.

Dengan adanya tulisan ini Penulis berharap mampu memberikan informasi mengenai faktor yang dapat mempengaruhi keberhasilan pembelajaran bahasa Inggris siswa sehingga secara tidak langsung membantu pencapaian tujuan utama pembelajaran bahasa Inggris di sekolah maupun di tingkat universitas.

\section{PEMBAHASAN}

1. Penelitian Terdahulu

Considine dan Zappala pada tahun 2002 menyatakan bahwa tingkat sosial - ekonomi keluarga memiliki pengaruh terhadap pencapaian akademik peserta didik, penelitian ini merupakan hasil dari menganalisa data lebih dari 3.000 peserta didik yang memiliki latar belakang keluarga yang berbeda tingkatan sosial ekonominya ${ }^{3}$.

${ }^{3}$ Considine, G. and G. Zappala.2002. .Factors Influencing the Educational Performance of Students from Disadvantaged Backgrounds., in T. Eardley and B. Bradbury, eds, Competing 
Sedangkan dalam penelitian Haryanto pada tahun 1999 yang berjudul "Motivation and Learning Strategies of a good Indonesian EFL learner", menyimpulkan bahwa ada dua faktor utama dalam kesuksesan Indra dalam pembelajaran bahasa Inggris, yaitu; motivasi dan strategi pembelajaran ${ }^{4}$.

Fasilitas sekolah menunjang keberhasilan siswa, udara yang bersih, pencahayaan yang menunjang, ketenangan, kenyamanan, dan keamanan lingkungan sekolah merupakan hal-hal yang penting dalam pencapaian keberhasilan pembelajaran ${ }^{5}$

\section{FAKTOR YANG MEMPENGARUHI KEBERHASILAN PEMBELAJRAN BAHASA INGGRIS}

1) Menurut Ahli Linguistik

a) Schumann's Acculturation Model ${ }^{6}$

Penelitian Schumann tahun 1978 menyatakan bahwa perbedaan sosial dan psychologicalantara pelajar dan komunitas bahasa target merupakan faktor utama dalam pencapaian pembelajaran.

(2) Faktor Sosial

Visions:Refereed Proceedings of the National Social Policy Conference 2001. University of New South Wales, Sydney.

${ }^{4}$ Haryanto, 1999.Motivation and Learning Strategies of a good Indonesian EFL learner.Unpublished Dissertation.PPs IKIP Jakarta.

${ }^{5}$ Cash, C. 1993, “A Study of the Relationship between School

Building Condition and Student Achievement and

Behavior.'Unpublished doctoral dissertation, Virginia Polytechnic

Institute and State University.

${ }^{6}$ Schumann, J.H. 1978. Understanding Second and Foreign

Language Learning. Rowley, Massachussets: Newbury House

Publisher. 
Ada delapan variabel sosial yang dapat mempengaruhi kualitas pembelajaran bahasa asing oleh pelajar.

(a)Dominasi Sosial

Ketika kelompok bahasa target lebih mendominasi secara politik, budaya, tehnis, maupun secara ekonomi dari pada kelompok bahasa pertama, hal ini yang mendorong penguasaan bahasa target dapat dikuasai dengan cepat dan mudah oleh kelompok bahasa pertama. Hal ini dapat dibuktikan dengan masih adanya negara bekas jajahan portugis yang menggunakan bahasa purtugis sebagai bahasa nasional mereka seperti Timor Leste dan Brazil.

(b) Asimilasi, Preservasi, dan Adaptasi

Jika kelompok bahasa pertama memilih proses asimilasi sebagai strategi integrasi mereka dalam pengusaan bahasa target secara menyeluruh bersama budaya bahasa target, yang berarti melepaskan gaya hidup dan nilai kehidupan mereka, kemudian menggantinya dengan gaya hidup dan nilai kehidupan kelompok bahasa target, kemudian melakukan proses preservasi yang berarti menjaga hal tersebut terus menerus dan yang terakhir mengadaptasi hal tersebut kedalam kehidupan mereka sehari-hari.

(c) Enclosure

Enclosurebermakna pengaruh intensitas kelompok bahasa pertama berinteraksi dengan kelompok bahasa target, berbagi dalam struktur sosial yang sama seperti di sekolah, fasilitas rekreasi, pasar, maupun di kantor mampu membantu memfasilitasi penguasaan bahasa target.

(d)Cohesiveness

Saat kelompok bahasa pertama konsisten bersatu tetap menjaga bahasa mereka dari pengaruh bahasa asing, menutup diri dari pengaruh luar. Hal ini tercermin dari beberapa suku 
pedalaman di Nusantara yang berkomitmen menjaga budaya dan bahasa nenek moyang mereka sampai sekarang.

(e) Size

Penguasaan bahasa target akan lebih mudah jika kelompok bahasa target lebih dominan daripada kelompok bahasa pertama dan interaksi antar mereka lebih intensif.

(f) Congruence

Bahasa target akan lebih mudah dikuasai saat budaya kelompok bahasa pertama sangat mirip dengan kelompok bahasa target, hal ini dapat dibuktikan dengan masyarakat suku Bugis mampu menguasai dengan mudah bahasa suku Makassar, begitu pula sebaliknya, karena budaya suku Bugis dan Makassar secara umum memiliki kemiripan.

(g)Attitude

Saat kelompok bahasa pertama dan kelompok bahasa target memiliki akhlak yang mulia saat berinteraksi, harmonis, dan mampu menumbuhkan rasa simpati satu sama lain, hal ini dapat memfasilitasi penguasaan bahasa target.

(h) Intended length of residence

Semakin lama kelompok bahasa pertama tinggal di lingkungan bahasa target semakin besar pula keinginan maupun kebutuhan mereka untuk menguasai bahasa target, oleh karena itu semua TKI yang pernah bekerja di luar negeri mampu menguasai bahasa negara tersebut.

Psychological Distance

Ada empat faktor kejiwaan yang termasuk dalam Schumann's model. Language shock, cultural shock, motivasi, dan ego yang memiliki peranan penting dalam penguasaan bahasa target. Jika Language shockdan cultural shocktidak mampu diimbangi oleh kelompok bahasa pertama, hal itu membatasi mereka dalam berinteraksi dengan kelompok bahasa target yang berimbas pada kesusahan mereka dalam penguasaan bahasa target. 
A.M. Dakhalan, Faktor yang Mempengaruhi Keberhasilan Peserta|111

\section{(3) Ellis's Classification ${ }^{7}$}

Menurut Ellis, faktor yang mempengaruhi keberhasilan siswa dalam penguasaan bahasa ada dua faktor; personal factors dan general factors. Personal Factors yaitu; kedinamisan kelompok, sikap terhadap guru, dan materi pengajaran. Sedangkan General Factors yaitu;usia, kecerdasan, kesadaran, motivasi, dan tabiat.

(4) Teori Spolsky ${ }^{8}$

Beberapa faktor yang memberikan kontribusi terhadap kesuksesan penguasaan bahasa baru dirumuskan oleh Spolsky menjadi; $\mathrm{Kf}=\mathrm{Kp}+\mathrm{A}+\mathrm{M}+\mathrm{O}$. Kf bermakna pengetahuan yang didapatkan selama hidup, Kp sebagai simbol pengetahuan tentang bahasa target dan bahasa pertama, A disimbolkan sebagai faktor physiological, biological, intellectual, dan cognitive yang dapat mempengaruhi seseorang, $\mathrm{M}$ berarti karakter, akhlak, motivasi, dan kesadaran seseorang, dan $\mathrm{O}$ sebagai seberapa sering seseorang mendapatkan kesempatan untuk menggunakan bahasa target tersebut.

Berdasarkan teori Spolsky sebelumnya, gambaran mengenai permasalahan pembelajaran bahasa Inggris di sekolah maupun kampus di Indonesia salahsatunya adalah kesempatan penerapkan bahasa Inggris tersebut, bahasa pada dasarnya sebagai alat berkomunikasi, jika hanya dipelajari tanpa wadah penerapan tidak akan berjalan maksimal.

(5) Griffiths ${ }^{9}$

${ }^{7}$ Ellis, R. 1985. Understanding Second Language Acquisition.

Oxford: OUP. h. 3-11

${ }^{8}$ Spolsky, Bernard. 1989. Conditions for Second Language

Learning. Oxford: Oxford University Press

${ }^{9}$ Griffiths, Carol. 2008. Lesson from Good Language Learner.

Cambridge University Press.h.19-25 
Faktor yang mempengaruhi pelajar dalam penguasaan bahasa Inggris menurut Griffiths dalam bukunya sebagai berikut;

(1) Motivasi

Menurut Ushioda ${ }^{10}$ pelajar yang sukses adalah pelajar yang termotivasi, motivasi merupakan dorongan jiwa yang mampu menggerakkan seseorang untuk menentukan pilihan dan sanggup menerima konsekuensinya. Tanpa motivasi kesuksesan pelajar dalam penguasaan bahasa target akan sulit tercapai.

Motivasi merupakan kombinasi dari usaha dan keinginan untuk menguasai bahasa target secara sadar yang terefleksikan dalam tindakan. Menurut Harmer ${ }^{11}$ motivasi merupakan dorongan dari dalam untuk mencapai sesuatu.

Jenis-jenis motivasi

Motivasi dapat dikategorikan dalam beberapa kategori, berdasarkan asal motivasi tersebut dapat dikategorikan menjadi dua kategori; intrinsic motivation dan extrinsic motivation.

Menurut Marsh $^{12}$, ada tiga faktor internal dalam intrinsic motivation, yangpertama adalah need, need atau kebutuhan dapat memandu seseorang untuk mencapai tujuan pembelajaran, menguasai bahasa Inggris dapat membantu peserta didik berbaur dalam kehidupan sosial mereka dan meningkatkan daya saing mereka. Yang kedua adalah interest, ketertarikan mempunyai peranan penting dalam meningkatkan level motivasi peserta didik, jika peserta didik tertarik mempelajari bahasa Inggris, maka mereka sanggup dengan mudah mencapai objek pembelajaran.

${ }^{10}$ Griffiths, Carol 2008..h.131-142.

${ }^{11}$ Harmer, Jeremy.1988.The Practice of English Language Teaching. Edinburgh gate Harlow, England. Longman.

${ }^{12}$ Marsh, Colin.1996. Hand Book for Beginning Teachers.

South Melbourne, Australia. Longman. 
Yang ketiga adalah faktor enjoyment, hal ini juga mempunyai peranan penting dalam meningkatkan motivasi belajar peserta didik, jika peserta didik menikmati proses pembelajaran maka materi pembelajaran akan dipahami dengan mudah.

Extrinsic Motivation merupakan kebalikan dari IntrinsicMotivation, Extrinsic Motivation dipengaruhi oleh faktor external. Marsh ${ }^{13}$ menjelaskan bahwa motivasi yang muncul karena faktor external akan menghasilkan respon tertentu. Harmer ${ }^{14}$ menjelaskan bahwa faktor external yang menyebabkan munculnya Extrinsic Motivation bisa berupa harapan finansial, lulus ujian, ataupun masa depan.

(2) Usia

Usia peserta didik juga mempengaruhi perkembangan bahasa mereka, hal ini telah dikemukakan oleh beberapa Peneliti, salah satunya adalah Snow dan Hoefnagel-Hohle ${ }^{15}$ yang meneliti tentang proses perkembangan bahasa Belanda anak kecil (asing) yang tinggal menetap di Belanda. Mereka menemukan bahwa, beberapa bulan sejak anak kecil itu tiba di Belanda, siswa yang lebih tua jauh melampui mereka dalam penguasaan bahasa baru, namun setelah setahun, mereka telah mampu melampaui level siswa yang lebih tua. Penemuan yang lain oleh Harley ${ }^{16}$, dia menemukan bahwa meskipun siswa yang lebih tua mampu menunjukkan penguasaan lebih mengenai sistem verb dari siswa yang lebih muda, namun setelah 1.000 jam instruksi siswa muda mampu mencapai level yang lebih tinggi pada akhirnya.

(3) Learning Style

\footnotetext{
${ }^{13}$ Marsh, Colin.1996.

${ }^{14}$ Harmer, Jeremy.1988

${ }^{15}$ Marsh, Colin. 1996.

${ }^{16}$ Marsh, Colin. 1996.
} 
Menurut Curry ${ }^{17}$ untuk mendefinisikan konsep learning style agak membingungkan karena begitu luasnya variasi tingkatan dan cakupan pembelajaran, lingkungan sekolah, dan perilaku. Namun menurut Dunn ${ }^{18}$ faktor yang mempengaruhi learning style adalahlingkungan, emosional, sosiological, dan physiological.

(4) Personality

Personality diartikan sebagai aspek tingkah laku seseorang, cara bersikap, keyakinan, cara berpikir, dan perasaan yang menjadi ciri khas dan yang membedakan seseorang dengan orang yang lain. ${ }^{19}$

Teori personality pertama kali dipaparkan oleh Carl Jung ${ }^{20}$ seorang ahli psychology asal Swiss. Dia mengelompokkan kedalam empat kelompok yang lebih dikenal sebaga The Dichotomous Scale. Kelompok pertama Extraversion - Introversion. Yang kedua Sensing - Intuition, ketiga Thinking - Feeling, dan yang terakhir Judging Perceiving

(5) Gender

Gender tidak hanya dipandang sebagai penggolongan biologically saja, akan tetapi digunakan juga untuk mengkonstruksi aturan sosial sejak mereka lahir kemudian bersosialisasi dengan lingkungan sekitar sesuai dengan budaya mereka. Sosialisasi berdasarkan gender merupakan kunci utama yang menentukan lelaki atau wanita mampu menguasai bahasa target dengan cepat.

(6) Strategi

Strategi pembelajaran bahasa menurut kamus besar Oxford ${ }^{21}$ adalah "Specific actions taken by the learner to make learning easier, faster, more enjoyable, and more self-directed, more effective,

\footnotetext{
${ }^{17}$ Marsh, Colin. 1996.

${ }^{18}$ Marsh, Colin.1996.

${ }^{19}$ Marsh, Colin.1996.

${ }^{20}$ Marsh, Colin. 1996.

${ }^{21}$ Marsh, Colin, Oxford Advanced Learner's Dictionary. 2005. Oxford: Oxford University Press.
} 
A.M. Dakhalan, Faktor yang Mempengaruhi Keberhasilan Peserta|115

and more transferable to new situations". Sadangkan menurut Bialystok ${ }^{22}$ strategi pembelajaran bahasa dapat digambarkan sebagai cara yang dipilih untuk mendapatkan informasi tambahan yang digunakan untuk meningkatkan kompetensi pada bahasa target.

(7) Beliefs

Menurut Siegel ${ }^{23}$ beliefs merupakan "mental constructions of experience”, pengetahuan tidak hanya terbentuk dari sebuah proses cognisi tapi juga melaluipengalaman.

(8) Budaya

Perbedaan etnis, budaya, dan kewarganegaraan membentuk karakter peserta didik yang memberikan pengaruh terhadap kedinamisan kelas. Hal ini menjadi pertimbangan utama bagi guru untuk mengoptimalkan proses pembelajaran bagi semua peserta didik.

(9) Aptitude

Rubin ${ }^{24}$ menyatakan bahwa Aptitude, motivasi, dan kesempatan merupakan tiga faktor yang memberikan kesuksesan berbeda dalam pembelajaran bahasa. Ranta ${ }^{25}$ menambahkan bahwa pengakomodasian karakter kecerdasan peserta didik oleh guru dapat membantu peserta didik menjadi pelajar bahasa yang sukses.

(10) Status sosial - ekonomi

Status sosial-ekonomi dapat menggambarkan posisi kehidupan sosial seseorang di lingkungan tempatnya tinggal, saat digunakan untuk mengukur tingkat keberhasilan pembelajaran peserta didik, hal itu fokus kepada status sosial-ekonomi orang tua maupun keluarga. Status sosial-ekonomi dapat diukur dengan tingkat

\footnotetext{
${ }^{22}$ Marsh, Colin.1996. .

${ }^{23}$ Marsh, Colin. 1996.

${ }^{24}$ Marsh, Colin.1996.

${ }^{25}$ Marsh, Colin. 1996.
} 
pendidikan, jenis pekerjaan, penghasilan, maupun kekayaan seseorang.

\section{MENURUT AL-QURAN}

a) Peran Keluarga:

QS. At-Tahrim: 6

Arttinya:

Hai orang-orang yang beriman, peliharalah dirimu dan keluargamu dari api neraka yang bahan bakarnya adalah manusia dan batu; penjaganya malaikat-malaikat yang kasar, keras, dan tidak mendurhakai Allah terhadap apa yang diperintahkan-Nya kepada mereka dan selalu mengerjakan apa yang diperintahkan.

Sebagaimana Firman Allah Swt dalam Alquran surat AlKahfi ayat 46.

Artinya: "Harta dan anak-anak adalah perhiasan kehidupan dunia, tetapi amanah-amanah yang kekal lagi soleh adalah lebih baik pahalanya di sisi Tuhanmu serta lebih baik untuk menjadi harapan." (QS. Al-Kahfi ayat 46).

Ayat di atas paling tidak mengandung dua pengertian. Pertama, mencintai harta dan anak merupakan fitrah manusia, karena keduanya adalah perhiasan dunia yang dianugerahkan Sang Pencipta. Kedua, hanya harta dan anak yang shaleh yang dapat dipetik manfaatnya.Anak harus dididik menjadi anak yang shaleh (dalam pengertian anfa'uhum linnas) yang bermanfaat bagi sesamanya.

Beberapa penelitian yang dikemukakan oleh beberapa ahli, seperti yang di kemukakan dalam majalah rumah tangga dan kesehatan bahwa "Orang tua berperan dalam menentukan hari depan anaknya. Secara fisik supaya anak-anaknya bertumbuh sehat dan berpostur tubuh yang lebih baik, maka anak-anak harus diberi makanan yang bergizi dan 
seimbang.Secara mental anak-anak bertumbuh cerdas dan cemerlang, maka selain kelengkapan gizi perlu juga diberi motivasi belajar disertai sarana dan prasarana yang memadai.Sedangkan secara sosial suapaya anak-anak dapat mengembangkan jiwa sosial dan budi pekerti yang baik mereka harus di beri peluang untuk bergaul mengaktualisasikan diri, memupuk kepercayaan diri seluasluasnya. Bila belum juga terpenuhi biasanya karena soal teknis seperti hambatan ekonomi atau kondisi sosial orang tua.“(Sabri Alisuf : 1995 :24 )

Orang tua yang tidak memperdulikan anak-anaknya, orang tua yang tidak memenuhi tugas-tugasnya sebagai ayah dan ibu, akan sangat berpengaruh terhadap keberlangsungan hidup anak-anaknya. Terutama peran seorang ayah dan ibu adalah memberikan pendidikan dan perhatian terhadap anakanaknya.Sebagaimana dikemukakan, "Perkembangan jiwa dan sosial anak yang kadang-kadang berlangsung kurang mantap akibat orang tua tidak berperan selayaknya.Naluri kasih sayang orang tua terhadap anaknya tidak dapat dimanifestasikan dengan menyediakan sandang, pangan, dan papan secukupnya.Anak-anak memerlukan perhatian dan pengertian supaya tumbuh menjadi anak yang matang dan dewasa."(Depdikbud, 1993 : 12 ).

Dalam berbagai penelitian para ahli dapat dikemukakan beberapa hal yang perlu di berikan oleh orang tua terhadap anaknya, sebagai mana diungkapkan sebagai berikut:

1. Respek dan kebebasan pribadi.

2. Jadikan rumah tangga nyaman dan menarik.

3. Hargai kemandiriannya.

4. Diskusikan tentang berbagai masalah. 
5. Berikan rasa aman, kasih sayang, dan perhatian.

6. Anak-anak lain perlu di mengerti. (Ahmadi Abu, $1991: 44)$

Dari beberapa poin yang telah dikemukakan para ahli di atas dapat dipahami bahwa banyak hal yang harus dilakukan oleh orang tua dalam melakukan tugas serta peran mereka sebagai orang tua, yaitu harus respek terhadap gerakgerik anaknya serta memberikan kebebasan pribadi dalam mengembangkan bakat serta menggali potensi yang ia miliki termasuk yang paling mendasar adalah kemampuan bahasa, orang tua dalam menjalani rumah tangga juga harus dapat menciptakan rumah tangga yang nyaman, dan orang tua harus memiliki sikap demokratis. Ia tidak boleh memaksakan kehendak sehingga anak akan menjadi korban, ia harus betulbetul mengerti, memahami, serta memberikan kasih sayang dan perhatian yang penuh. Orang tua yang tidak memenuhi peran dan tidak menjalankan tugas tugasnya seperti apa yang di jelaskan di atas, maka anak-anak hidupnya menjadi terlantar, ia akan mengalami kesulitan dalam menggali potensi dan bakat yang ia miliki. Conny Semiawan dan kawan-kawan menyatakan bahwa, "Orang tua perlu membina anak agar mau berprestasi secara optimal, karena kalau tidak berarti suatu penyia-nyiaan terhadap bakatbakatnya.Pembinaan dilakukan dengan mendorong anak untuk mencapai prestasi yang sesuai dengan kemampuannya.Ada pula orang tua, karena tingkat pendidikan mereka sendiri terbatas, karena acuh tak acuh atau karena kurang memperhatikan anak, pendidikan anak, tidak peka dalam pengamatan ciri-ciri kemampuan anaknya".

Seorang anak sangat memerlukan bimbingan kedua orang tuanya dalam mengembangkan bakat serta menggali 
potensi yang ada pada diri anak tersebut. Dalam rangka menggali potensi dan mengembangkan bakat dalam diri anak maka seorang anak memerlukan pendidikan sejak dini

Conny Semiawan dan kawan-kawan menyatakan, "Orang tua perlu menciptakan lingkungan rumah atau keluarga yang serasi, selaras, dan seimbang dengan kehadiran anak-anak berbakat.Disamping itu perlu menyiapkan sarana lingkungan fisik yang memungkinkan anak mengembangkan bakatnya.Perlu sikap demokrasi juga dalam memberikan banyak larangan, dirangsang untuk menjadi mandiri dan percaya diri." (Semiawan, 1990 : 31-55).

Lingkungan keluarga sangat mempengaruhi bagi pengembangan kepribadian anak dalam hal ini orang tua harus berusaha untuk menciptakan lingkungan keluarga yang sesuai dengan keadaan anak.Dalam lingkungan keluarga harus diciptakan suasana yang serasi, seimbang, dan selaras, orang tua harus bersikap demokrasi baik dalam memberikan larangan, dan berupaya merangsang anak menjadi percaya diri. Pendapat lain tentang peran dan tugas orang tua adalah sebagai berikut, "Komunikasi ibu dan ayah dalam keluarga sangat menentukan pembentukan pribadi anak-anak di dalam dan di luar rumah. Selanjutnya dikatakan bahwa seorang ayah umumnya berfungsi sebagai dasar hukum bagi putra-putrinya, sedangkan seorang ibu berfungsi sebagai landasan moral bagi hukum itu sendiri."(Ali, 1995 : 30).

Tugas-tugas serta peran yang harus dilakukan orang tua tidaklah mudah, salah satu tugas dan peran orang tua yang tidak dapat dipindahkan adalah mendidik anak-anaknya. Sebab orang tua memberi hidup anak, maka mereka mempunyai kewajiban yang teramat penting untuk mendidik anak mereka.Jadi, tugas sebagai orang tua tidak hanya sekadar menjadi perantara makhluk baru dengan kelahiran, 
tetapi juga memelihara dan mendidiknya, agar dapat melaksanakan pendidikan terhadap anak-anaknya, maka diperlukan adanya beberapa pengetahuan tentang pendidikan.

Berdasarkan beberapa pendapat yang telah dikemukakan di atas penulis dapat memberikan suatu kesimpulan bahwa orang tua harus memperhatikan lingkungan keluarga, sehingga dapat menciptakan lingkungan yang sehat, nyaman, serasi serta lingkungan yang sesuai dengan keadaan anak. Komunikasi yang dibangun oleh orang tua adalah komunikasi yangn baik karena akan berpengaruh terhadap kepribadian anak-anaknya.

b) Pengaruh Motivasi:

Artinya

“Sesungguhnya Allah tidak merobah keadaan sesuatu kaum sehingga mereka merobah keadaan[768] yang ada pada diri mereka sendiri. dan apabila Allah menghendaki keburukan terhadap sesuatu kaum, Maka tak ada yang dapat menolaknya; dan sekali-kali tak ada pelindung bagi mereka selain Dia.

Dari ayat di atas kita bisa mengambil kesimpulan bahwa ternyata motivasi yang paling kuat adalah dari diri seseorang.Motivasi sangat berpengaruh dalam gerakgerik seseorang dalam setiap tindak-tanduknya.

Dalam kaitannya dengan tingkah laku keagamaan motivasi tersebut penting untuk dibicarakan dalam rangka mengetahui apa sebenarnya latar belakang suatu tingkah laku keagaman yang dikerjakan seseorang. Disini peranan motivasi itu sangat besar artinya dalam bimbingan dan mengarahkan seseorang terhadap tingkah laku keagamaan. Namun demikian ada motivasi tertentu yang sebenarnya timbul dalam diri manusia karena terbukanya hati manusia terhadap hidayah Allah. Sehingga orang tersebut menjadi orang yang beriman dan 
kemudian dengan iman itulah ia lahirkan tingkah laku keagaman

Ada beberapa peran motivasi dalam kehidupan manusia sangat banyak, diantaranya:

1. Motivasi sebagai pendorong manusia dalam melakukan sesuatu, sehingga menjadi unsur penting dan tingkah laku atau tindakan manusia

2. Motivasi bertujuan untuk menentukan arah dan tujuan hidup

3. Motivasi berpungsi sebagai penguji sikap manusia dalam beramal benar atau salah sehingga bisa dilihat kebenarannya dan kesalahanya

4. Motivasi berfungsi sebagai penyeleksi atas perbuatan yang akan dilakukan oleh manusia baik atau buruk. Jadi motivasi itu berfungsi sebagai pendorong, penentu, penyeleksi dan penguji sikap manusia dalam kehidupanya.

Dan diantara 4 diatas yang paling dominan adalah peran motivasi yang pertama (Ramayulis: Psikologi Agama: 102)

Ibrahim el-fiky dalam bukunya menyebutkan bahwa ketika seseorang memiliki motivasi dan dorongan psikologi maka semangat akan lebih banyak kemampuan akan lebih besar dan pengetahuan akan lebih baik. Sebaliknya, jika semangat lemah maka sorang itu tidak akan memiliki kemampuan dan konsentrasi hanya bertuju untuk hal negatif saja. Maka pekerjaanpun jadi jelek.

Ada 3 jenis motivasi menurut Ibrahim El-fiky:

1. Motivasi hidup

Motivasi hiduplah mendorong manusia untuk kebutuhan primernya, misalnya 
makanan,air, dan udara jika kebutuhan primer kurang maka ada motivasi dasar didalam dirinya yang mengingatkan syarafnya di otak tentang kehususan=kehususan tentang kekurangan ini yang akan mendorong seseorang untuk semangat berkerja demi memenuhi kekurangan ini.

\section{Motivasi Eksternal}

Motivasi ini berasal dari eksternal seperti motivator ulung, atau teman-teman, anggota keluarga, majalahmajalah,buku, atau para pemimpin kita di kantor. Namun motivasi ini cepat hilangnya

\section{Motivasi Internal}

Jenis motivasi ini paling kuat dan paling lama tahanya. Karena dengan motivasi internal kita bisa mengendalikan kekuatan internal yang akan menuntun kita untuk mewujudkan pencapaian-pencapian besar.

Motivasi kuat untuk hidup sukses bahagia, sejahtra, dewasa, bermakna dan unggul akan mengerakan kita untuk selalu besikap hidup positip dan produktif ( Ibrahim El-Fiky, 10 Kesys To Ultimate Sucsses:11-13)

\section{PENUTUP}

Berdasarkan kajian teori linguistik dan Al-Qur'an sebelumnya, penulis dapat menyimpulkan bahwa faktor yang dapat mempengaruhi keberhasilan peserta didik dalam pembelajaran bahasa Inggris adalah; intelektual, motivasi, fasilitas, kebijakan pemerintah, keluarga, dan lingkungan. 
A.M. Dakhalan, Faktor yang Mempengaruhi Keberhasilan Peserta|123

\section{Referensi:}

Cash, C. 1993, "A Study of the Relationship between School Building Condition and Student Achievement and Behavior.'Unpublished doctoral dissertation, Virginia Polytechnic Institute and State University.

Considine, G. and G. Zappala. 2002. .Factors Influencing the Educational Performance of Students from Disadvantaged Backgrounds., in T. Eardley and B. Bradbury, eds, Competing Visions:Refereed Proceedings of the National Social Policy Conference 2001.University of New South Wales, Sydney.

Ellis, R. 1985. Understanding Second Language Acquisition. Oxford: OUP.

Griffiths, Carol. 2008. Lesson from Good Language Learner. Cambridge University Press.

Harmer, Jeremy.1988.The Practice of English Language Teaching. Edinburgh gate Harlow, England. Longman.

Haryanto, 1999.Motivation and Learning Strategies of a good Indonesian EFL learner.Unpublished Dissertation.PPs IKIP Jakarta.

Marsh, Colin.1996. Hand Book for Beginning Teachers. South Melbourne, Australia. Longman.

McKay, S. L. 2003. Toward An Appropriate EIL Pedagogy: Reexamining Common ELT Assumption. International Journal of Applied Linguistics, 13(1), pp. 1-22. Oxford Advanced Learner's Dictionary. 2005.

Oxford: Oxford University Press.

Schumann, J.H. 1978. Understanding Second and Foreign Language Learning.Rowley, Massachussets: Newbury House Publisher. 
124 Rausyan Fikr, Vol. 12 No.1 Juni 2016: 105 - 124

Spolsky, Bernard. 1989. Conditions for Second Language Learning. Oxford: Oxford University Press

Yuwono, G. 2005. English Language Teaching in Decentralised Indonesia: Voices from The Less Priviledged Schools. Paper presented at the AARE 2005 International Education Research Conference. 